\title{
Ethical and Social Issues for Health Care Providers in the Intensive Care Unit during the Early Stages of the COVID-19 Pandemic in Japan: a Questionnaire Survey
}

\author{
Yusuke Seino $^{1} \cdot$ Yayoi Aizawa $^{1} \cdot$ Atsushi Kogetsu $^{1} \cdot$ Kazuto Kato $^{1}$ (D)
}

Received: 11 August 2021 / Revised: 9 October 2021 / Accepted: 12 October 2021 /

Published online: 15 November 2021

(C) The Author(s) 2021

\begin{abstract}
This questionnaire-based observational study was conducted in July 2020 with the aim of understanding the ethical and social issues faced by health care providers (HCPs) registered with the Japanese Society of Intensive Care Medicine in intensive care units (ICUs) during the coronavirus disease (COVID-19) pandemic. There were 200 questionnaire respondents, and we analyzed the responses of 189 members who had been involved in COVID-19 treatment in ICUs. The ethical and social issues that HCPs recognized during the pandemic were difficulties in the decision-making process with patients' families, limitations of life-sustaining treatment, lack of palliative care, and inadequate mental support for patients' families and HCPs. Regarding decision-making on issues of clinical ethics during the pandemic, more than half of the respondents thought they had failed to provide sufficient palliative care to patients and responded that they experienced moral distress. The free-text responses on moral distress revealed issues such as unusual treatment and care, restricted visits, challenging situations for HCPs, and psychological burden. Additionally, $38.1 \%$ of respondents experienced episodes of social prejudice or discrimination and $4.7 \%$ experienced a shortage of medical resources. Our study result shows that the moral distress of HCPs was caused by difficulties in patient-centered decision-making and insufficient medical care to patients and their families. These were caused mainly by a lack of communication due to the stronger implementation of infection control measures. We believe that it is important to address ethical and social issues during a pandemic in order to provide appropriate medical care and prevent burnout among HCPs.
\end{abstract}

Keywords COVID-19 $\cdot$ Moral distress $\cdot$ Clinical ethics $\cdot$ Ethical issues $\cdot$ Social issues · Intensive care unit · Japan

Kazuto Kato

kato@eth.med.osaka-u.ac.jp

Extended author information available on the last page of the article 


\section{Background}

The COVID-19 outbreak, which was first reported in China, advanced rapidly worldwide and was officially declared a pandemic by the World Health Organization on March 11, 2020 (Mannelli 2020; WHO 2020). During the initial phase of the pandemic, countries such as Italy (Mannelli 2020; Remuzzi and Remuzzi 2020) and the USA (Richardson et al. 2020) were unable to adequately respond to the increasing number of patients and the shortage of medical resources, including intensive care unit (ICU) beds and ventilators (Truog et al. 2020; Emanuel et al. 2020), which led to a humanitarian crisis in those regions (Nacoti et al. 2020).

In Japan, a state of emergency was declared for the first time on April 7, 2020, owing to the spread of COVID-19 mainly in urban areas. Infection control measures, such as refraining from going out, closing schools, testing for COVID-19, and isolating those who tested positive, were implemented. There was a significant impact on the healthcare delivery system, especially in the ICU. Although Japan's healthcare system has a large number of general beds, the number of ICU beds is small (OECD 2020). Therefore, as the number of critically ill patients increases, the medical capacity in ICUs is likely to be exceeded (Japan Medical Association COVID-19 Expert Meeting 2020). During the initial phase of the pandemic, although the number of seriously ill patients was lower in Japan than in other countries, facilities accepting critically ill COVID-19 patients were limited because of a lack of adequate infection control measures and equipment shortages. Therefore, the burden on some facilities became increasingly severe.

Even at normal times in the ICU, HCPs encounter ethical and social issues, such as decision-making at the end of life and palliative care (Makino et al. 2014). Addressing these issues is essential because it will lead to the provision of desirable medical care to patients and their families. In addition, challenging ethical situations, exposure to high patient mortality, and difficult daily workloads can lead to excessive stress for HCPs in the ICU, leading to burnout syndrome (Kerlin et al. 2020). Especially, moral distress has been identified as one of the significant causes of burnout (Colville et al. 2019). It is thought to be caused by HCPs' inability to provide appropriate treatment and care owing to institutional restrictions (Cacchione 2020; Corley 2002; Morley et al. 2020). HCP burnout has far-reaching and significant consequences, not only for the personal well-being of HCPs but also for patient care and the healthcare system (Kerlin et al. 2020). Therefore, it is important to identify the ethical and social issues in the ICU and to address the resulting moral distress and burnout.

Although it is likely that the changes in social conditions by the COVID-19 pandemic have made the ethical and social issues faced by HCPs in ICUs more apparent and serious, the actual experiences and perceptions of the HCPs are not clearly understood. In this study, we administered a questionnaire to HCPs regarding the ethical and social issues and moral distress they experienced before and during the pandemic. 


\section{Objectives}

The purpose of this study was to understand what ethical and social issues ICU HCPs face in Japan during the COVID-19 pandemic and suggest possible measures to deal with them.

\section{Methods}

\section{Study Design and Participants}

This was a cross-sectional, questionnaire-based observational study of registered Japanese Society of Intensive Care Medicine (JSICM) members who were contacted using the JSICM mailing list. The questionnaire was sent to the 10,767 members (7717 physicians, 2122 nurses, 484 clinical engineers, and 444 others), and the electronic survey was conducted anonymously using Google Forms. We found no publicly available data on the percentage of ICU HCPs who had been engaged in the COVID-19 treatment at the time of the survey, so we were unable to identify the demographics of the population. Initially, this study intended to include all members of JSICM. However, as there were few responses from members who had not been involved in the COVID-19 treatment, it was difficult to make statistical comparisons with those who were involved in the treatment of COVID-19. Hence, in this paper, we present only the results of the analysis of responses of members who have been involved in the treatment of COVID-19.

This study was approved by the Clinical Trial Group Committee of the JSICM and the Ethics Review Committee of Osaka University (Ethics Review No. 20095). Consent for the survey was obtained when a participant answered survey questions.

The survey was conducted over a 2-week period, between July 6 and 19, 2020, when the number of infected people in Japan had decreased and the state of emergency was lifted.

\section{Questionnaire}

The survey questions pertained to (1) respondent demographics; (2) ethical and social issues encountered in the ICU during normal times (i.e., before the COVID-19 pandemic); (3) changes in the medical care system, ethical and social issues, and moral distress experienced in the ICU during the pandemic; and (4) allocation of medical resources during the pandemic. The questionnaire included 34 items in multiple-choice and free-text response formats (Table S1). 


\section{Data Analysis}

Quantitative data were analyzed using EZR statistical software (Saitama Medical Center, Jichi Medical University, Saitama, Japan) (Kanda 2013). The $\chi^{2}$ test was used to compare groups. $P<0.05$ was considered statistically significant.

Qualitative data obtained from the free-text response was examined using inductive content analysis (Elo and Kyngäs 2008). One author (YS) assigned the text content of all qualitative data into categories and subcategories and coded the text in terms of content. When an individual's response spanned multiple categories, it was classified into such. Two other authors (YA and KK) audited the original inductive content analysis and recategorized it, as necessary. Discrepancies were discussed until consensus was reached. The coding was agreed upon by all authors for consistency and validity.

\section{Results}

\section{Respondent Characteristics}

Two hundred respondents answered the questionnaire. Two duplicates and nine respondents who had not been involved in the treatment of patients with confirmed or suspected COVID-19 cases were excluded. In the end, 189 responses were analyzed. The respondents' characteristics are summarized in Table 1. Only $7.4 \%$ of the respondents indicated that their institutions did not have a mechanism for examining clinical ethical issues.

\section{Ethical and Social Issues and Moral Distress in Japanese ICUs in Normal Times}

Regarding the ethical and social issues they encountered in ICUs during normal times before the pandemic, the respondents' answers were as follows: limitation of life-sustaining treatment $(66.1 \%)$, difficulties in decision-making with the patient's family $(61.9 \%)$, with HCPs $(55.6 \%)$, and with patients $(43.4 \%)$ (multiple-choice question) (Fig S1).

The most common method for making decisions on clinical ethical issues among HCPs was multidisciplinary meetings (47.6\%). Only $7.4 \%$ of respondents answered that decisions were made by a physician alone (Table S2).

Moral distress was routinely experienced by half of the respondents when working in the ICU. Moral distress was significantly more common among nurses than among physicians $(P=0.003)$ (Table 2$)$. 
Table 1 Characteristics of respondents $(N=189)$

\begin{tabular}{|c|c|}
\hline Variable & $N(\%)$ \\
\hline \multicolumn{2}{|l|}{ Profession } \\
\hline Physicians & $97(51.3 \%)$ \\
\hline Nurses & $65(34.4 \%)$ \\
\hline Clinical engineers & $19(10.0 \%)$ \\
\hline Physical and occupational therapists & $7(3.7 \%)$ \\
\hline Pharmacist & $1(0.5 \%)$ \\
\hline \multicolumn{2}{|l|}{ Years of ICU experience } \\
\hline No experience & $1(0.5 \%)$ \\
\hline $1-2$ years & $11(5.8 \%)$ \\
\hline $3-5$ years & $19(10.1 \%)$ \\
\hline $6-10$ years & $44(23.2 \%)$ \\
\hline $11-20$ years & $83(44.0 \%)$ \\
\hline More than 21 years & $31(16.4 \%)$ \\
\hline \multicolumn{2}{|l|}{ Working experience in the intensive care unit } \\
\hline Currently working full-time in the intensive care unit & $103(54.5 \%)$ \\
\hline Currently working concurrently in the intensive care unit & $47(24.9 \%)$ \\
\hline $\begin{array}{l}\text { Worked in the intensive care unit in the past and currently indirectly in intensive care } \\
\text { unit work }\end{array}$ & $26(13.8 \%)$ \\
\hline $\begin{array}{l}\text { Worked in the intensive care unit in the past and not currently involved in intensive care } \\
\text { unit work }\end{array}$ & $12(6.3 \%)$ \\
\hline $\begin{array}{l}\text { Has not worked in the intensive care unit in the past but currently involved indirectly in } \\
\text { intensive care unit work }\end{array}$ & $1(0.5 \%)$ \\
\hline \multicolumn{2}{|l|}{ Type of intensive care unit before the coronavirus disease (COVID-19) pandemic } \\
\hline Open intensive care unit $^{\mathrm{a}}$ & $28(14.8 \%)$ \\
\hline Semi-closed intensive care unit ${ }^{b}$ & $107(56.7 \%)$ \\
\hline Closed intensive care unit ${ }^{\mathrm{c}}$ & $54(28.5 \%)$ \\
\hline \multicolumn{2}{|l|}{ Facilities } \\
\hline University hospital & $90(47.6 \%)$ \\
\hline Public hospitals & $54(28.6 \%)$ \\
\hline Other & $45(23.8 \%)$ \\
\hline \multicolumn{2}{|l|}{ Mechanisms for examining clinical ethical issues (multiple choice) } \\
\hline An independent hospital ethics committee & $122(64.6 \%)$ \\
\hline Other ethics committees & $41(21.7 \%)$ \\
\hline An ethics consultation system & $34(18.0 \%)$ \\
\hline No mechanism for considering clinical ethical issues & $14(7.4 \%)$ \\
\hline
\end{tabular}

${ }^{a}$ Intensivists are the patient's primary attending physician

${ }^{b}$ Mandatory critical care consultation (intensivists are not the patient's primary attending physician, but every patient admitted to the intensive care unit receives a critical care consultation) or elective critical care consultation (intensivists are involved in the care of the patient only when the attending physician requests a consultation)

${ }^{\mathrm{c}}$ No critical care physician (intensivists are unavailable) 
Table 2 Number of health care providers who experienced moral distress in ICU care in normal times and during the coronavirus disease pandemic

\begin{tabular}{llllll}
\hline & Overall $(N=189)$ & $\begin{array}{l}\text { Physicians } \\
(N=97)\end{array}$ & Nurses $(N=65)$ & Others $(N=27)$ & \\
\hline $\begin{array}{l}\text { Normal times } \\
\begin{array}{l}\text { During the pan- } \\
\text { demic }\end{array}\end{array}$ & $107(56.6 \%)$ & $47(48.4 \%)^{*}$ & $46(70.8 \%)^{*}$ & $9(33.3 \%)$ & $* P=0.003$ \\
\hline
\end{tabular}

${ }^{*} \chi^{2}$ tests

$I C U$, intensive care unit

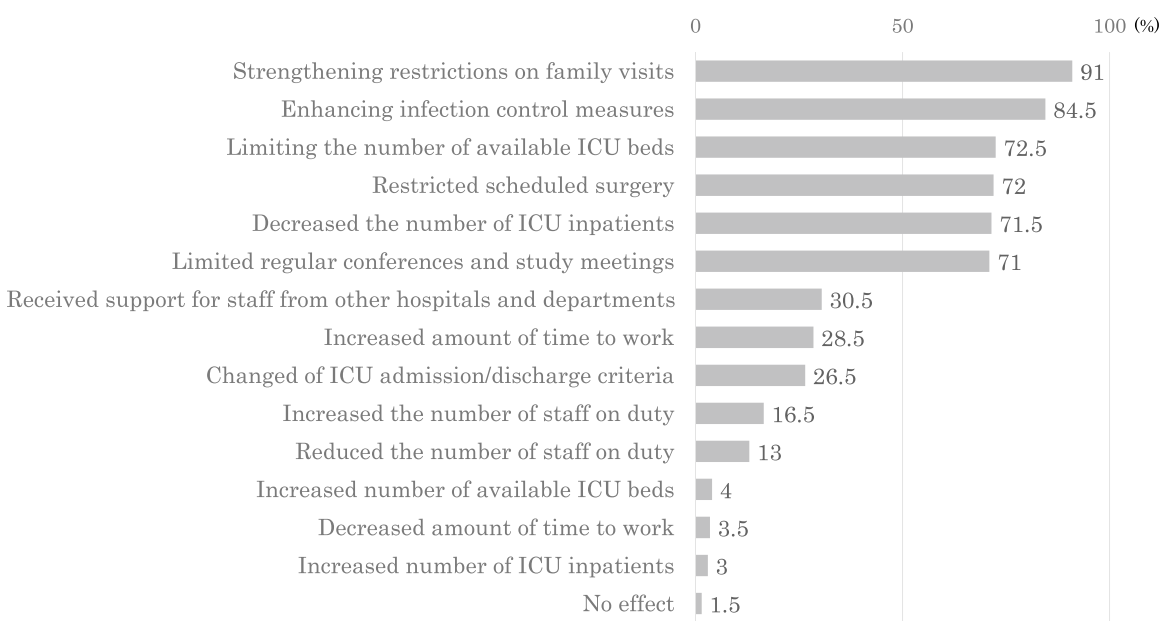

Fig. 1 Impact of the coronavirus disease pandemic on the medical care system (multiple-choice question)

\section{Ethical and Social Issues and Moral Distress in Japanese ICUs during the COVID-19 Pandemic}

In this section, we examined the influence on the medical care system and the ethical and social issues experienced by HCPs during the COVID-19 pandemic.

Respondents mentioned changes in the medical care system due to the COVID19 pandemic in the following order: strengthening restrictions on family visits, enhancing infection control measures, limiting the number of available ICU beds, and restricting scheduled surgery (Fig. 1).

The ethical and social issues faced while providing medical care that HCPs identified as being more problematic during the COVID-19 pandemic were difficulties in the decision-making process with patients' families, limitations of life-sustaining treatment, lack of palliative care, inadequate mental support for the patients' families, and mental support for HCPs (Fig. 2).

The decision-making method regarding clinical ethical issues among HCPs remained mostly unchanged during the COVID-19 pandemic (Table S2). 


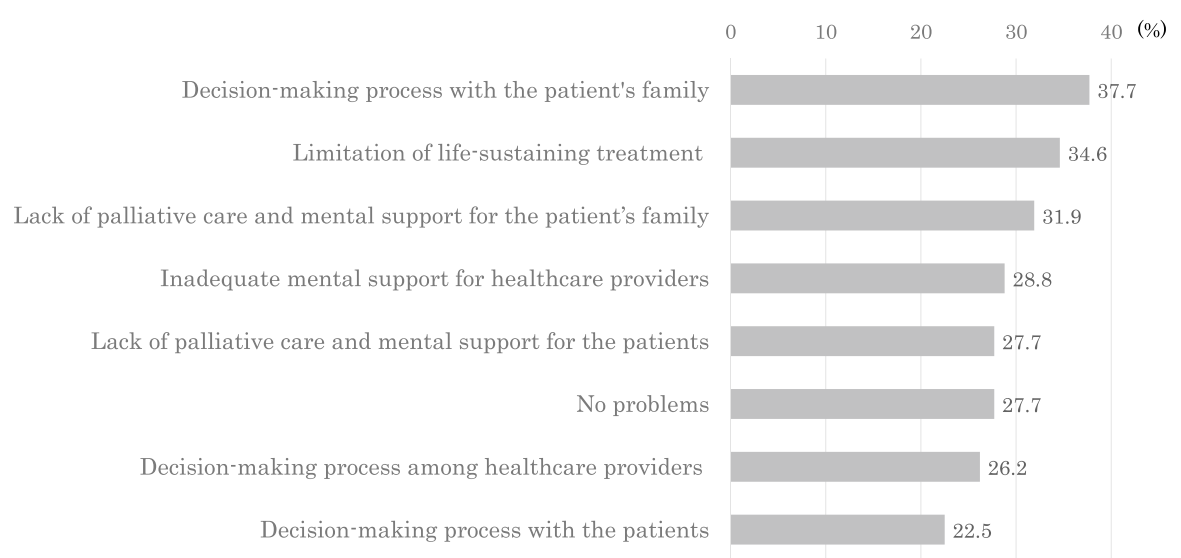

Fig. 2 Ethical and social issues related to providing medical care recognized by health care providers more during the COVID-19 pandemic than in normal times (multiple-choice question)

When making decisions in situations where clinical ethical issues arose during the COVID-19 pandemic, more than half of the respondents said they had failed to provide sufficient palliative care to patients as well as mental support and appropriate information to both patients and their families (Fig. S2). They also said that patients and their families could not speak openly with HCPs about their thoughts and concerns, and it was difficult for the HCPs to understand them. The main reasons for insufficient care, as described in the free-text responses, include visiting restrictions, increased implementation of infection control measures, anxiety about COVID-19, lack of communication between HCPs, patients, and their families, inability to confirm patients' wishes, and the need for unusual care.

More than half of the HCPs experienced unusual moral distress during the pandemic. The proportion of HCPs experiencing unusual moral distress during a pandemic was significantly higher among nurses than among physicians $(P<0.001)$ (Table 2).

Seventy-six free-text responses on moral distress were classified into five categories (Table 3). The most common responses were unusual treatment and care such as limited contact with patients and deep sedation and muscle relaxation, to prevent infection among HCPs. Many respondents also answered that patients and their families are unable to meet owing to restricted visits.

Regarding whether they experienced social prejudice or were discriminated against as a HCP during the COVID-19 pandemic, 38.1\% answered that they had experienced an episode of prejudice or discrimination. Among them, 19.6\% experienced a mental burden. Meanwhile, $28.6 \%$ of the respondents said that, while they did not experience prejudice or discrimination, they hesitated to directly interact with others, and $31.7 \%$ said they did not experience prejudice or discrimination.

Regarding advanced preparations for the allocation of medical resources necessary for life support, $20.1 \%$ of the affiliated facilities prepared in-facility guidelines, and $50.3 \%$ of the respondents discussed necessary medical resource allocation beforehand. Of the respondents, $4.7 \%$ experienced a shortage of medical resources to the extent 


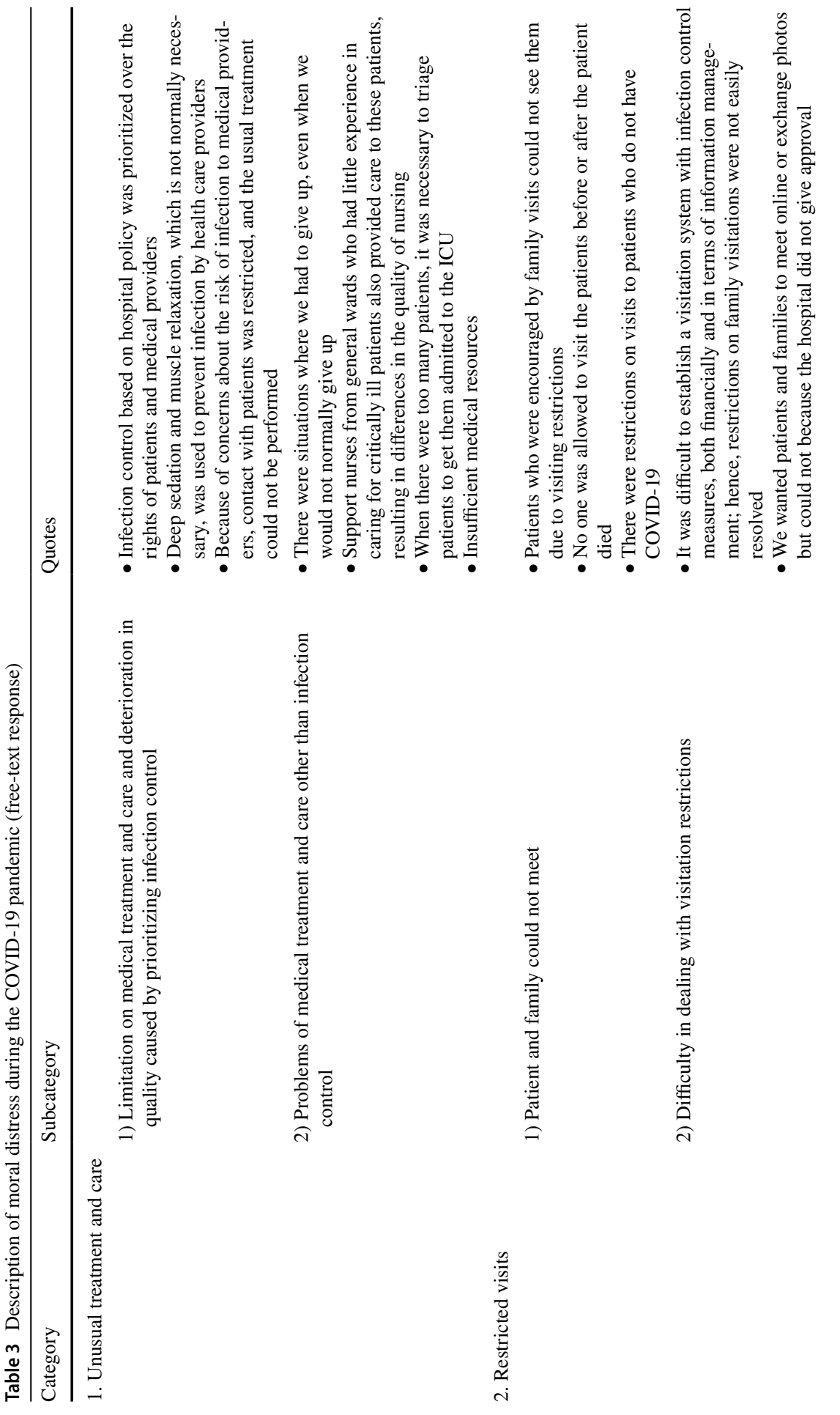




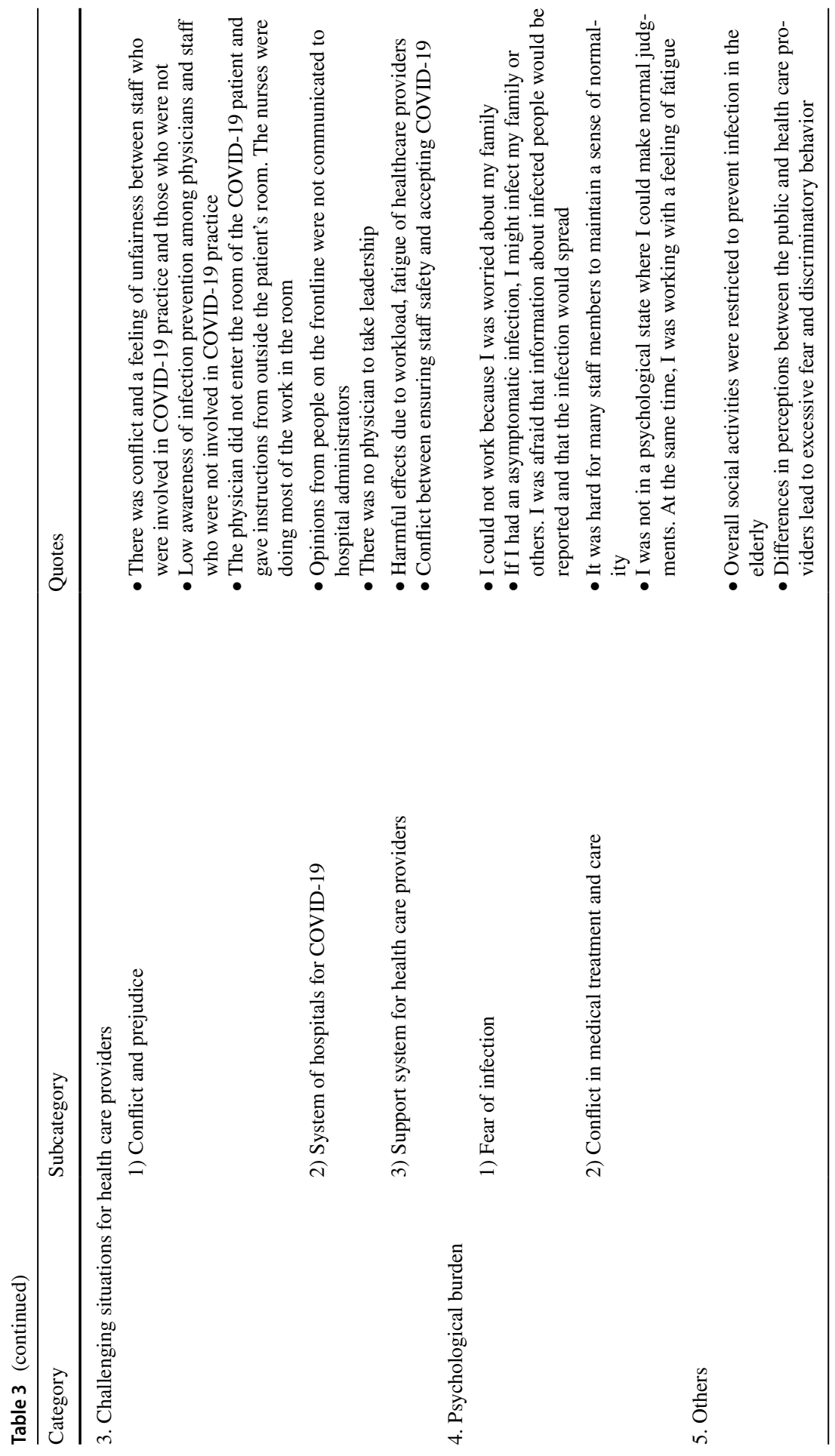


that necessary treatment and care could not be provided. On the contrary, 5.8\% of the respondents were able to receive support, such as patient transfer to another facility; $18.5 \%$ were able to increase medical resources; and $24.9 \%$ were able to provide care with existing medical resources. For $43.9 \%$ of the respondents, the shortage of medical resources was not a concern. The medical resources (including medical personnel) that were in shortage included personal protective equipment (PPE) required for medical procedures (70.9\%), nurses $(45.0 \%)$, physicians $(33.3 \%)$, and ICU beds $(28.0 \%)$ (multiple-choice question).

\section{Discussion}

This questionnaire-based study investigated the ethical and social issues encountered in Japanese ICUs and how these changed during the COVID-19 pandemic. To the best of our knowledge, this has not been previously reported. According to the results of this study, ICU HCPs became aware of various ethical and social issues and experienced moral distress during the COVID-19 pandemic.

Since there are no official statistics on the number of ICU HCPs involved in the treatment of COVID-19 patients in Japan, it is difficult to identify how many of the JSICM members were engaged in COVID-19 treatment at the time of the survey. However, according to the limited official statistical data, while the total number of ICU beds in Japan is about 7000, the maximum number of critically ill patients up until July 2020, the end point of the questionnaire, was only about 330 per day. Judging from this, we estimate that only a small number of HCPs in the ICU were involved in the treatment of COVID-19 patients. Therefore, despite the limited number of responses, we believe that the results of this survey are meaningful as they reflect the situation in the early stages of the COVID-19 pandemic in Japan.

\section{Ethical and Social Issues and Moral Distress in Japanese ICUs During the COVID-19 Pandemic}

One of the impacts of the COVID-19 pandemic on Japanese ICUs was that visitation restrictions and increased implementation of infection control measures made it difficult for patients, their families, and HCPs to communicate with each other. Furthermore, because of the pandemic, it was necessary to provide treatment and care with unusual restrictions, and HCPs experienced moral distress from not being able to provide sufficient treatment to patients. HCPs also experienced discrimination against themselves, as well as shortages of medical resources. These ethical and social issues can be highly stressful for HCPs and may cause burnout.

\section{Communication}

In order to make patient-centered decisions, it is necessary to have opportunities to provide sufficient information to patients and their families and have discussions 
based thereon. However, during the COVID-19 pandemic, communication between HCPs, patients, and their families became difficult.

Communication with other HCPs is important so that they can discuss the medical validity of treatments and the best interests of patients. In Japan, it has been previously reported that decisions regarding patient treatment are often made by physicians alone (Yaguchi et al. 2005). However, our study found that many ICUs held multidisciplinary team meetings to decide on treatment policies, rather than physicians alone making such decisions during normal times before the pandemic. Furthermore, it was also shown that the multidisciplinary approach established during normal times was maintained even during the pandemic. However, $26.2 \%$ of respondents experienced ethical and social issues during the decision-making process with other HCPs more than normal times during the pandemic (Fig. 2). This means that it is not enough to maintain the multidisciplinary approach in order to make better decisions, but that it is necessary to actively attempt to understand the intentions of patients and their families and to have discussions with other HCPs even in situations with limited resources and time.

Communication among patients, their families, and HCPs is essential for patientcentered decision-making, but during the pandemic, it was difficult to provide the medical care that patients and their families hoped for as a result of insufficient communication. As described in the Nursing Guidelines of the JSICM (Japanese Society of Intensive Care Medicine 2020; Japan Geriatrics Society 2020), to maintain communication under visitation restrictions, remote visits using telephones, electronic media, and information and communication technology should be considered alternatives. Some respondents experienced moral distress because the hospital did not give approval for such remote alternatives (Table 3). This indicates that the employment of new technology sometimes requires organizational and policy initiatives.

The United Nations has also mentioned the importance of mental health support for affected individuals and their families during the COVID-19 pandemic (United Nations 2020). In addition to the usual support provided by physicians and nurses to patients and their families, highly specialized psychological support by psychiatrists may lead to improved communication quality.

Communication between the patients and their families was also impaired. Owing to the rapid deterioration of patients' conditions caused by COVID-19, there was sometimes not enough time to confirm a patient's intentions. Further, the patients and their families were unable to spend the end-of-life period together because of visitation restrictions. The importance of advance care planning (ACP) and end-oflife discussions has been emphasized previously in the context of COVID-19 (Kim and Grady 2020; Curtis et al. 2020; Japan Geriatrics Society 2020). Even though communication is often limited due to the COVID-19 pandemic, engaging in such processes would make treatment and care more preferable for patients (Kim and Grady 2020).

Efforts such as strengthening the quantity and quality of communication and having ACP discussions are always important in the ICU. However, we consider that the necessity for these has become even more obvious during the COVID-19 pandemic. We believe that regular efforts to improve communication would be beneficial for pandemic conditions. 


\section{Conflicts Experienced by Health Care Providers}

During the COVID-19 pandemic, there were situations in which it was necessary to reduce contact with patients to prevent the spread of infection, deepen patient sedation more than necessary, and refrain from certain kinds of medical care such as rehabilitation (Nacoti et al. 2020). Furthermore, conflicts also occurred owing to differences in positions and roles among workers, and as a result, unusual additional mental stress was experienced. In addition, regarding infection prevention, staff members also had to avoid close contact, leaving few opportunities for them to express their thoughts and feelings. We speculate that these conflicts led to additional mental stress and moral distress among HCPs during the COVID-19 pandemic. Hence, supporting the mental health of these individuals is a critical part of the public health response (Walton et al. 2020) because it could lead to the prevention of burnout.

\section{Discrimination Experienced by Health Care Providers During the COVID-19 Pandemic}

This study found that $38.1 \%$ of HCPs who participated in the study faced social discrimination. It was also found that, even in the hospital, there was a sense of discrimination and inequality between those who were providing COVID-19 medical treatment and those who were not. Social discrimination has also been reported elsewhere in Japan (Japanese Association for Disaster Medicine 2020; Japanese Government New Coronavirus Infectious Disease Control Subcommittee 2020). Although efforts to increase understanding for HCPs and infected persons, as well as to eliminate discrimination, are being made primarily by the National Infectious Disease Control Subcommittee (Japanese Government New Coronavirus Infectious Disease Control Subcommittee 2020), further measures are needed to deal with the issues.

\section{Allocation of Medical Resources}

Although Japan had fewer patients with COVID-19 than many other countries (Watanabe 2020), and $70 \%$ of respondents said that their institutions had prepared in advance for the allocation of medical resources, in actual fact, medical resources turned out to be insufficient in the early stages of the pandemic in Japan. Regarding the kinds of medical resources that were in shortage, $70 \%$ of the respondents indicated that PPE was lacking. Despite the importance of securing PPE to protect the safety of HCPs, there was a worldwide shortage of PPE (Ranney et al. 2020; Kleinpell et al. 2020). HCPs were extremely concerned for their own health as well as that of their families (Kleinpell et al. 2020). In the free-text responses of this survey, respondents also described situations where they were not only concerned about the health of themselves and their family members, but they also felt a conflict between ensuring the safety of their staff and accepting COVID-19 patients. The lack of PPE was thought to have caused additional mental stress to the HCPs in the early stages of the pandemic in Japan. At present in Japan, the shortage of PPE is improving, but the situation is changing as there are concerns about the shortage of medical resources such as inpatient beds and ventilators. 
In fact, $4.7 \%$ of the respondents reported that they were not able to provide necessary treatment due to a lack of medical resources. Further, nearly $50 \%$ of the respondents took various measures to cope with the shortage of medical resources, such as trying to increase medical resources, transferring to another facility, and receiving support. It is clear that many of them were just barely able to cope with the shortage of medical resources, suggesting that a potential problem was occurring. After this survey was conducted, due to the rapid increase in the number of patients with COVID-19, the healthcare delivery system has collapsed in some areas, creating a situation in which critically ill patients cannot be admitted to the ICU (Sasagawa and Kobayashi 2021). At present, the allocation of medical resources is becoming a more serious issue, and it is highly likely that ethical and social issues will emerge as a result. While there is a global discussion on the allocation of limited medical resources such as ventilators and ICU beds (Mannelli 2020; Truog et al. 2020; Emanuel et al. 2020; Solnica et al. 2020), it has not been sufficiently discussed in Japan. During pandemics, the burden of choosing who is eligible for invasive treatments such as ventilators should not be concentrated on the frontline HCPs, so there is an immediate need to have a discussion concerning allocation in Japan.

\section{Limitations and Future Challenges}

This survey shows the status of members of JSICM who are engaged in COVID-19 treatment during the period of the survey. In Japan, HCPs who are not members of JSICM are also working in ICUs, especially physicians from other departments and nurses are often not members. A limitation of this study is that it may not reflect the situation of HCPs who are not members of the JSICM.

Although we received many opinions in the free-text responses, it was difficult to conduct a detailed qualitative analysis. This was because the information in the questionnaire alone was limited in its ability to capture the context and intent of the statements regarding the episodes and perceptions experienced by each individual.

Further qualitative research is needed to pursue how HCPs have responded to the ethical and social issues that arose in Japanese ICUs during the pandemic. In addition, the situation related to the COVID-19 pandemic in Japan has changed dramatically. Therefore, the ethical and social issues faced by HCPs in the ICU are continually changing, and further research is needed to capture these changes.

\section{Conclusions}

This study provided insight into the ethical and social issues encountered in Japanese ICUs during the COVID-19 pandemic. The ethical and social issues that we identified during the COVID-19 pandemic were mainly caused by the difficulties in communication between patients and their families owing to visitation restrictions and enhanced infection control measures. In addition, it was found 
that moral distress was caused by having to provide unusual treatment and care to patients, as well as by conflicts arising between HCPs.

It is important to address the ethical and social issues identified in this study not only as individuals but also as medical organizations and society as a whole. To compensate for the limited contact with the patient's family, it may be effective to make use of virtual methods such as online meetings with supports by HCPs. As psychological support for medical personnel, it is important to create a system to regularly check the mental stress of HCPs and to proactively intervene with psychologists and psychiatrists. Furthermore, providing support by professionals of medical and clinical ethics to address the issues may also be helpful. These measures could help lead to the provision of appropriate medical care for patients and their families even in difficult situations where there are various restrictions due to COVID-19 or other pandemics.

It is essential to understand the problems that cause the moral distress felt by HCPs and to take measures to alleviate them, which will help to improve working conditions and prevent burnout. We hope that the findings of this study and the future responses to these issues will lead to improvements in the medical care provided by Japanese ICUs in normal times as well as during pandemics.

Supplementary Information The online version contains supplementary material available at https://doi. org/10.1007/s41649-021-00194-y.

Acknowledgements We would like to thank Editage (www.editage.com) and Joshua Wittig for the English language editing. Part of the results of this study was presented at the 48th Annual Meeting of the Japanese Society of Intensive Care Medicine on February 14, 2021.

Author Contribution YS, YA, AK, and KK designed and planned the study. YS, YA, AK, and KK created the questionnaire and tested it. YS submitted the questionnaire and collected the data. YS performed the statistical analysis. YS wrote the first draft of the manuscript. All authors edited it and approved the final manuscript.

Funding This research was supported by the university grants for research allocated to the Department of Biomedical Ethics and Public Policy from the Graduate School of Medicine, Osaka University.

Availability of Data and Materials All data generated or analyzed during this study are included in this published article and its supplementary information files.

\section{Declarations}

Ethics Approval and Consent to Participate This study was approved by the ethical committee of Osaka University (No. 20095). Consent for the survey was obtained when a participant answered survey questions.

Consent for Publication The participants have consented to the submission of the research to the journal.

Conflict of Interest The authors declare no competing interests.

Open Access This article is licensed under a Creative Commons Attribution 4.0 International License, which permits use, sharing, adaptation, distribution and reproduction in any medium or format, as long as you give appropriate credit to the original author(s) and the source, provide a link to the Creative Commons licence, and indicate if changes were made. The images or other third party material in this article 
are included in the article's Creative Commons licence, unless indicated otherwise in a credit line to the material. If material is not included in the article's Creative Commons licence and your intended use is not permitted by statutory regulation or exceeds the permitted use, you will need to obtain permission directly from the copyright holder. To view a copy of this licence, visit http://creativecommons.org/licen ses/by/4.0/.

\section{References}

Cacchione, Pamela Z. 2020. Moral distress in the midst of the COVID-19 pandemic. Clinical Nursing Research 29: 215-216. https://doi.org/10.1177/1054773820920385.

Colville, G.A., D. Dawson, S. Rabinthiran, D.Z. Chaudy, and P.L. Perbins. 2019. A survey of moral distress in staff working in intensive care in the UK. Journal of Intensive Care Society 20: 196-203. https://doi.org/10.1177/1751143718787753.

Corley, Mary C. 2002. Nurse moral distress: A proposed theory and research agenda. Nursing Ethics 9: 636-650. https://doi.org/10.1191/0969733002ne557oa.

Curtis, Randall J., Erin K. Kross, and Renee D. Stapleton. 2020. The importance of addressing advance care planning and decisions about do-not-resuscitate orders during novel coronavirus 2019 (COVID19). JAMA 323: 1771-1772. https://doi.org/10.1001/jama.2020.4894.

Elo, Satu, and Helvi Kyngäs. 2008. The qualitative content analysis process. Journal of Advanced Nursing 62: 107-115. https://doi.org/10.1111/j.1365-2648.2007.04569.x.

Emanuel, Ezekiel J., Govind Persad, Ross Upshur, Beatriz Thome, Michael Parker, Aaron Glickman, Cathy Zhang, Connor Boyle, Maxwell Smith, and James P. Phillips. 2020. Fair allocation of scarce medical resources in the time of COVID-19. New England Journal of Medicine 382: 2049-2055. https://doi.org/10.1056/NEJMsb2005114.

Japan Geriatrics Society. 2020. Recommendations for the best medical care and care for the elderly during the COVID-19 epidemic (in Japanese). https://www.jpn-geriat-soc.or.jp/coronavirus/pdf/covid_ teigen.pdf. Accessed 3 Aug 2021.

Japan Medical Association COVID-19 Expert Meeting. 2020. COVID-19 Task Force on Intensive Care Units, interim report (in Japanese). https://www.covid19-jma-medical-expert-meeting.jp/topic/1910. Accessed 3 Aug 2021.

Japanese Association for Disaster Medicine. 2020. Statement against unjustified criticism of medical personnel engaged in dealing with the new coronavirus infection (in Japanese). https://jadm.or.jp/sys/_ data/info/pdf/pdf000121_1.pdf. Accessed 3 Aug 2021.

Japanese Government New Coronavirus Infectious Disease Control Subcommittee. 2020. Working Group on Prejudice. Discrimination and Privacy 1st (in Japanese). https://www.cas.go.jp/jp/seisaku/ful/ wg_h_1.pdf. Accessed 3 Aug 2021.

Japanese Society of Intensive Care Medicine. 2020. Nursing Q \& A for COVID-19 patients in ICU (in Japanese). https://www.jsicm.org/news/upload/COVID-19_nursing_Q\&A_v2.pdf. Accessed 3 Aug 2021.

Kanda, Y. 2013. Investigation of the freely available easy-to-use software EZR' for medical statistics. Bone Marrow Transplantation 48: 452-458. https://doi.org/10.1038/bmt.2012.244.

Kerlin, Meeta Prasad, McPeake Joanne, and Mark E. Mikkelsen. 2020. Burnout and Joy in the Profession of Critical Care Medicine. Critical Care 24: 98. https://doi.org/10.1186/s13054-020-2784-z.

Kim, Scott Y.H., and Christine Grady. 2020. Ethics in the time of COVID: What remains the same and what is different. Neurology 94: 1007-1008. https://doi.org/10.1212/WNL.0000000000009520.

Kleinpell, Ruth, David M. Ferraro, Ryan C. Maves, Sandra L. Kane, Richard Branson Gill, Steven Greenberg, et al. 2020. Coronavirus Disease 2019 Pandemic Measures: Reports From a National Survey of 9,120 ICU Clinicians. Critical Care Medicine 48: e846-e855. https://doi.org/10.1097/ccm.00000 00000004521.

Makino, Jun, Shigeki Fujitani, Bridget Twohig, Steven Krasnica, and John Oropello. 2014. End-of-life considerations in the ICU in Japan: Ethical and legal perspectives. Journal of Intensive Care 2: 9. https://doi.org/10.1186/2052-0492-2-9.

Mannelli, Chiara. 2020. Whose life to save? Scarce resources allocation in the COVID-19 outbreak. Journal of Medical Ethics 46: 364-366. 
Ministry of Health, Labour and Welfare (Japan). 2018. Report of medical in the final stages of life (in Japanese). https://www.mhlw.go.jp/toukei/list/dl/saisyuiryo_a_h29.pdf. Accessed 3 Aug 2021.

Ministry of Health, Labour and Welfare (Japan). 2017. Hospital bed function report for 2017. (in Japanese). https://www.mhlw.go.jp/stf/seisakunitsuite/bunya/0000055891.html. Accessed 3 Aug 2021.

Ministry of Health, Labour and Welfare (Japan). 2020. Domestic COVID-19 outbreak situation (in Japanese). https://www.mhlw.go.jp/stf/covid-19/kokunainohasseijoukyou.html. Accessed 3 Aug 2021.

Ministry of Health, Labour and Welfare (Japan). 2018. Guidelines for the medical and care decision process in the final stages of life (in Japanese). https://www.mhlw.go.jp/file/04-Houdouhappyou-10802 000-Iseikyoku-Shidouka/0000197701.pdf. Accessed 3 Aug 2021.

Morley, Georgina, Denise Sese, Prabalini Rajendram, and Cristie Cole Horsburgh. 2020. Addressing caregiver moral distress during the COVID-19 pandemic. https://doi.org/10.3949/ccjm.87a.ccc047.

Nacoti, Mirco, Andrea Ciocca, Angelo Giupponi, Pietro Brambillasca, Federico Lussana, Michele Pisano, Giuseppe Goisis, Daniele Bonacina, Francesco Fazzi, Richard Naspro, Luca Longhi, Maurizio Cereda, and Carlo Montaguti. 2020. At the epicenter of the COVID-19 pandemic and humanitarian crises in Italy: Changing perspectives on preparation and mitigation. NEJM Catalyst, 21 March 2020. https://catalyst.nejm.org/doi/full/10.1056/CAT.20.0080. Accessed 28 Oct 2021.

Organization for Economic Co-operation and Development. 2020. Beyond containment: Health systems responses to COVID-19 in the OECD. http://www.oecd.org/coronavirus/policy-responses/beyondcontainment-health-systems-responses-to-covid-19-in-the-oecd-6ab740c0/. Accessed 3 Aug 2021.

Ranney, Megan L., Valerie Griffeth, and Ashish K. Jha. 2020. Critical Supply Shortages. The Need for Ventilators and Personal Protective Equipment during the Covid-19 Pandemic. New England Journal of Medicine 382: e41. https://doi.org/10.1056/nejmp2006141.

Remuzzi, Andrea, and Giuseppe Remuzzi. 2020. COVID-19 and Italy: What next? Lancet 395: 12251228. https://doi.org/10.1016/S0140-6736(20)30627-9.

Richardson, Safiya, Jamie S. Hirsch, Mangala Narasimhan, James M. Crawford, Thomas McGinn, Karina W. Davidson, et al. 2020. Presenting characteristics, comorbidities, and outcomes among 5700 patients hospitalized with COVID-19 in the New York City area. JAMA 323: 2052-2059. https:// doi.org/10.1001/jama.2020.6775.

Sasagawa, Shohei, Taichi Kobayashi. 2021. Osaka hospital beds for serious COVID-19 cases now all filled up. Ashahi Shimbum, 15 April 2021. http://www.asahi.com/ajw/articles/14331155. Accessed 3 Aug 2021.

Solnica, Amy, Leonid Barski, and Alan Jotkowitz. 2020. Allocation of scarce resources during the COVID-19 pandemic: A Jewish ethical perspective. Journal of Medical Ethics 46: 444-446. https:// doi.org/10.1136/medethics-2020-106242.

Truog, Robert D., Mitchell Christine, and George Q. Daley. 2020. The toughest triage—allocating ventilators in a pandemic. New England Journal of Medicine 383: 1973-1975. https://doi.org/10.1056/ NEJMp2005689.

United Nations. 2020. Policy brief COVID-19 and the need for action on mental health. https://www.jspn. or.jp/uploads/uploads/files/activity/United_Nations20200513.pdf. Accessed 3 Aug 2021.

Walton, Matthew, Esther Murray, and Michael D. Christian. 2020. Mental health care for medical staff and affiliated healthcare workers during the COVID-19 pandemic. European Heart Journal: Acute Cardiovascular Care 3: 241-247. https://doi.org/10.1177/2048872620922795.

Watanabe, M. 2020. The COVID-19 Pandemic in Japan. Surgery Today 50: 787-793. https://doi.org/10. 1007/s00595-020-02033-3.

World Health Organization. 2020. Coronavirus disease (COVID-19) pandemic. https://www.euro.who. $\mathrm{int/en/health-topics/health-emergencies/coronavirus-covid-19/novel-coronavirus-2019-ncov.}$ Accessed 3 Aug 2021.

Yaguchi, Arino, Robert D. Truog, J. Randall Curtis, John M. Luce, Mitchell M. Levy, and Christian Melot. 2005. International differences in end-of-life attitudes in the intensive care unit: Results of a survey. Archives of Internal Medicine 165: 1970-1975. https://doi.org/10.1001/archinte.165.17. 1970 .

Publisher's Note Springer Nature remains neutral with regard to jurisdictional claims in published maps and institutional affiliations. 


\section{Authors and Affiliations}

Yusuke Seino $^{1}$ - Yayoi Aizawa ${ }^{1} \cdot$ Atsushi Kogetsu $^{1} \cdot$ Kazuto Kato $^{1}$

1 Department of Biomedical Ethics and Public Policy, Graduate School of Medicine, Osaka University, Suita, Osaka, Japan 